\title{
Audiology
}

\section{Verbal task and motor responses (VTMR) in an adult hearing screening programme}

\author{
L'audiometria con risposte motorie nello screening uditivo di soggetti adulti \\ Federica Di Berardino ${ }^{1}$, Ivan Cortinovis ${ }^{2}$, Anna Gasbarre ${ }^{3}$, Eliana Filipponi ${ }^{3}$, Silvano Milani², Diego Zanetti ${ }^{1}$ \\ ${ }^{1}$ Audiology Unit, Fondazione IRCCS Ca' Granda Ospedale Maggiore Policlinico, Milan, Italy - Department of Clinical Sciences and \\ Community Health, University of Milan, Italy; ${ }^{2}$ Medical Statistics, Department of Clinical Sciences and Community Health, University \\ of Milan, Italy; ${ }^{3}$ UOC Direzione Professioni Sanitarie, Fondazione IRCCS Ca' Granda Ospedale Maggiore Policlinico, Department of \\ Clinical Sciences and Community Health, University of Milan, Italy
}

\section{SUMMARY}

The aim of this study was to test the efficacy of Verbal Tasks and Motor Responses (VTMR) speech audiometry in providing a rapid and true-to-life assessment of hearing-related problems as a single test in adult hearing screening programmes. The VTMR consists in manual execution of 5 verbal commands received by patients at different signal intensity levels and fixed masking noise; it provides a score of speech comprehension in noise. This was a prospective observational study in 916 individuals out of 1,300 volunteers (605 males, 695 females, aged $56 \pm 17$ years) who completed adult hearing screening. VTMR speech audiometry was performed at signal to noise $(\mathrm{S} / \mathrm{N})$ ratios of $0 \mathrm{~dB}$ and $-10 \mathrm{~dB}$. The difference between normal and hearing impaired subjects in terms of all the considered variables was statistically significant for pure-tone audiometry and VTMR testing. VTMR testing at a $\mathrm{S} / \mathrm{N}$ ratio of $-10 \mathrm{~dB}$ with a cut-off of four correctly executed tasks and was a rapid, feasible and efficient means of differentiating between normal and hearing impaired subjects. When used to screen hearing impaired subjects with participation restrictions, the sensitivity and specificity of the VTMR test rose to $90 \%$ and $62 \%$, respectively. The VTMR test in noise could be used as a stand-alone tool when screening for impairment and self-perceived participation restriction together.

KEY WORDS: speech audiometry, hearing screening, VTMR

\section{RIASSUNTO}

Lo scopo dello studio è di testare l'efficacia di un nuovo test di audiometria vocale a risposte motorie (VTMR) nel rumore da utilizzare per determinare l'handicap uditivo in programmi di screening per soggetti adulti. La VTMR consiste nell'esecuzione manuale di 5 comandi verbali ricevuti dal paziente a diverse intensità di segnale e fornisce un punteggio relativo alla comprensione nel rumore. In questo studio osservazionale prospettico $916 \mathrm{su}$ 1.300 volontari ( 605 maschi, 695 femmine, età media $56 \pm 17$ anni), sono stati sottoposti a uno screening uditivo con audiometria tonale liminare e VTMR ad un rapporto segnale/ rumore $(S / N)$ di 0 e $-10 \mathrm{~dB}$ HL. Risultati: la differenza tra soggetti normo-e ipoacusici, in funzione di tutte le variabili considerate, è risultata statisticamente significativa per la combinazione di audiometria tonale e VTMR. Il test VTMR con $S / N$ di $-10 \mathrm{~dB}$ è risultato essere uno strumento rapido, pratico ed efficiente nel differenziare tra soggetti normo- $e$ ipoacusici con un cut-off di 4 su 5 comandi verbali eseguiti correttamente. Nel sottogruppo dei pazienti con riferita limitazione della partecipazione sociale, la sensibilità e la specificità del test VTMR sono rispettivamente del $90 \%$ e del 62\%. La VTMR può essere utilizzata singolarmente nello screening di soggetti adulti per testare sia l'impairment uditivo che la limitazione sociale che ne consegue.

PAROLE CHIAVE: audiometria vocale con risposte motorie, VTMR, screening uditivo
Received: August 31, 2017

Accepted: March 28, 2018

Published on line: March 25, 2019

\section{Correspondence}

\section{Federica Di Berardino}

Audiology Unit, Department of Clinical Sciences and Community Health, Fondazione IRCCS Ca' Granda Ospedale Maggiore Policlinico, Università degli Studi di Milano, via Pace 9, 20122 Milan, Italy Tel. +3902 5503.3922. Fax +390250320754

E-mail: federica.diberardino@unimi.it

Funding

None.

Conflict of interest

The Authors declare no conflict of interest.

How to cite this article: Di Berardino F, Cortinovis I, Gasbarre A, et al. Verbal task and motor responses (VTMR) in an adult hearing screening programme. Acta Otorhinolaryngol Ital 2020;40:57-63. https://doi.org/10.14639/0392100X-1929

() Società Italiana di Otorinolaringoiatria e Chirurgia Cervico-Facciale

\section{(c) (i) $(9)$}

This is an open access article distributed in accordance with the CC-BY-NC-ND (Creative Commons Attribution-NonCommercial-NoDerivatives 4.0 International) license. The article can be used by giving appropriate credit and mentioning the license, but only for non-commercial purposes and only in the original version. For further information: https:// creativecommons.org/licenses/by-nc-nd/4.O/deed.en 


\section{Introduction}

Adult hearing screening programmes are currently increasing worldwide as a result of recent concern regarding the importance of monitoring hearing, increasing awareness of hearing loss and promoting behavioural change by enhancing patient involvement ${ }^{1,2}$. The techniques commonly used in adult hearing screening include anamnesis, visual inspection, pure-tone audiometry and self-assessment of hearing disability ${ }^{3}$.

Pure-tone audiometry can be used to screen individuals for hearing impairment, but not for hearing disability, whereas self-assement is used to measure participation restrictions, but may not accurately assess hearing disorders or impairment ${ }^{4}$. Furthermore, there is increasing evidence that the degree of measured peripheral hearing impairment (loss of function) may not completely reflect an individual's real communication performance (speech comprehension) and may provide only a partial picture of the real-life experience of the activity limitations and participation restrictions (handicap) ${ }^{5}$.

For this reason, the use of speech audiometry has been introduced in adult hearing screening in order to focus on the actual difficulties experienced by the individual with a hearing problem. These include speech communication difficulties, particularly in challenging listening situations where complications such as background noise, crowds or competing talkers are present ${ }^{6}$. However, pure-tone audiometry and speech audiometry together are not sufficient to measure level of participation and/or participation restriction and describe only partially the social consequences of hearing loss ${ }^{7}$.

The Verbal Tasks and Motor Responses (VTMR) speech audiometry test is an original test that was introduced in 2012 as a means of evaluating speech comprehension by soliciting the prompt execution of simple tasks (motor responses) using phonetically balanced verbal commands ${ }^{8}$. As already reported, it allows rapid evaluation of speech comprehension by assessing the ability to simultaneously process auditory and visual information and to perform simple motor tasks with three-dimensional and standardised objects resembling familiar tools. Therefore, the VTMR test differs from other speech tests, and in particular from the vowel-consonantvowel tests previously proposed for checking speech understanding in adult hearing screening ${ }^{6}$. We chose to use this test because it closely reflects real-life difficulties connected with understanding commands in noise and executing tasks and therefore might provide a measure of participation restriction in hearing impaired subjects.

The aim of this study was to test the efficacy of VTMR speech audiometry in providing rapid and true-to-life as- sessment of hearing-related problems when used alone to screen simultaneously for both hearing loss and self perceived participation restriction in adult hearing screening programs.

\section{Materials and methods}

Subjects

One thousand and three hundred volunteers ( 605 males, 695 females, $56 \pm 17$ years) were enrolled by a team of physicians and audiologists stationed in a mobile unit that travelled to 10 different locations in Milan, Italy. The event was promoted by the Public Health Department of the Municipality of Milan. The free programme of the deafness prevention campaign was advertised with flyers, posters and on the Internet. The subjects could make an appointment directly on site or by calling a free phone number. The locations were chosen in order to obtain a realistic sample of the entire urban community (city centre and suburbs, residential and industrial areas, peaceful and noisy neighbourhoods).

In accordance with American Speech-Language-Hearing Association (ASHA) guidelines ${ }^{3}$, exclusion criteria consisted of visual identification of physical abnormality of the outer ear, otoscopic identification of ear canal abnormality, cerumen impaction, previous ear surgery or otological disease (such as middle ear pathology e.g. acute otitis media, inactive or active chronic otitis media, congenital ear abnormalities or more than two acute episodes of vertigo or persisting dizziness). Patients with a positive history of psychiatric, neurologic disorders or mild cognitive impairment were excluded.

None of the interviewed subjects had previously taken part in hearing conservation programmes or training courses aimed at managing ear diseases and reducing the risk of hearing loss.

\section{Tests course}

After review of clinical history by a physicians, all volunteers were asked to complete an informative questionnaire on audiologic issues that measured their knowledge of managing and preventing ear disease and hearing loss ${ }^{11}$. Clinical otoscopy, consisting of visual inspection of the outer ear using clinical otoscopes, was used for otological evaluation of each subject to identify any individuals requiring medical referral and to determine candidacy for adult hearing screening. The Pass/Refer criteria used were:

- pass: normal results in both ears;

- refer: visual identification of any physical abnormality of the outer ear, or otoscopic identification of ear canal abnormality, or cerumen impaction, according to the ASHA guidelines ${ }^{3}$. 
All subjects underwent audiological evaluation with puretone audiometry for the frequencies of 500, 1,000, 2,000 and 4,000 $\mathrm{Hz}$ using an audiometer (Amplaid A177 plus, Amplifon, Milan, Italy) with TDH-49 headphones. Ambient noise levels inside the sound-treated booth were checked four times a day to verify that they did not exceed American National Standards Institute (ANSI) levels ${ }^{10}$. In order to comply with the ASHA guidelines, $500 \mathrm{~Hz}$ values have not been included in the analysis for its higher variability due to their influence on environmental noise ${ }^{3}$. Subjects'hearing was considered normal if responses to pure-tone air-conduction stimuli lower than $25 \mathrm{~dB} \mathrm{HL}$ at $1,000,2,000$ and $4,000 \mathrm{~Hz}$ were obtained in both ears or in the poorer ear, according to the ASHA guidelines ${ }^{3}$.

\section{VTMR test}

Once the first audiological phase of evaluation had been completed, an external CD player was connected to the audiometer and the VTMR test was played through two loudspeakers placed in front and at the back of the listener $\left(0^{\circ}\right.$ and $180^{\circ}$ azimuth), at a distance of $1 \mathrm{~m}$ from the subject, according to ANSI S3.6-2010 ${ }^{11}$. The VTMR test CD starts with a stereo calibration tone of $1 \mathrm{kHz}$ at $60 \mathrm{~dB}$ SPL lasting 30 seconds. The root-mean-squared (RMS) output level of the recorded voice is $60 \mathrm{~dB}$ SPL with a peak variation not exceeding $\pm 3 \mathrm{~dB}$ SPL.

The test consists of a set of familiar objects (a base, a hammer and a wooden structure with four sticks and five rings of different colours) and 20 lists of five simple tasks, all with the same level of motor execution difficulty, colour types and spectral frequency pattern (according to the Italian language), that are recorded on the $\mathrm{CD}$ with a pause of 8 seconds between each task (Fig. 1). The lists can be used randomly, since the choice of colours and objects was originally determined by a balance in the spectral frequency, and Fast Fourier analysis revealed no significant differ-

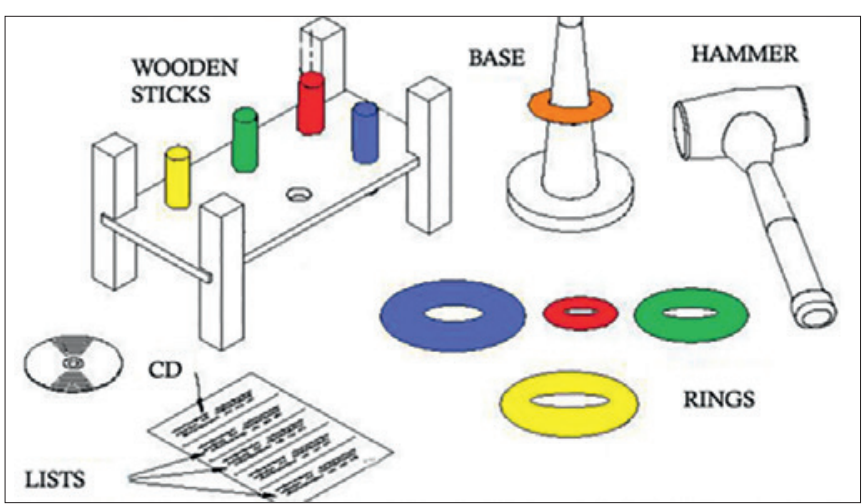

Figure 1. Equipment for VTMR test speech audiometry. ences in intensity for each frequency in the 20 lists ${ }^{8}$. Each correctly performed task receives a score of 20 , and the results obtained with each list are tallied as a percent-correct value of 100 for each list of five verbal tasks. Hereunder, we report two of the 5-task lists:

1. with the hammer, hit on the green stick once;

2. take the orange ring off the base;

3. pick up the yellow ring;

4. with the hammer, hit on the blue stick once and on the yellow stick once;

5. put the green ring onto the base.

1. with the hammer, hit on the yellow stick once and on the red stick once;

2. pick up the red ring;

3. take the green ring off the base;

4. put the red ring onto the base;

5. with the hammer, hit on the blue stick once.

After one training list, two lists of VTMR speech audiometry were randomly chosen and proposed to all subjects at two fixed $\mathrm{S} / \mathrm{N}$ ratios: $0 \mathrm{~dB}$ and $-10 \mathrm{~dB}$. The choice of $-10 \mathrm{~dB}$ of $\mathrm{S} / \mathrm{N}$ ratio was meant to check the speech comprehension behaviour in a worse noisy environment, especially when pure tone hearing was normal.

\section{Participation restriction questionnaires}

According to the ASHA guidelines, self-assessment screening of perceived hearing handicap and communicationspecific problems was carried out using the Hearing Handicap Inventory for the Elderly questionnaire, short form (HHIEsf) ${ }^{12}$. This inventory is commonly used to investigate the area of participation, in order to assess residual participation restrictions, i.e. the problems or barriers encountered during situations of daily life in which hearing plays a role ${ }^{13}$. It consists of 10 standardised questions including five social or situational items and five emotional response items. A response of "yes" is given 4 points, "sometimes" is given 2 points, and "no" is given 0 points; therefore, the HHIEsf scores range from 0 to 40 . According to the HHIEsf raw score handicap range, the post-hoc probability of hearing impairment is reported to be $13 \%$ for "no handicap" (08), 50\% in Mild-to-Moderate Handicap (10-24) and 84\% for Severe Handicap (26-40) ${ }^{14}$.

The study was approved by the Government Ethical Committee and the Health Department of Milan.

\section{Statistical analysis}

The validity of VTMR testing was assessed using the receiver operating characteristics (ROC) curve, the area un- 
der the ROC curve (AUC) and Youden's index. Multiple logistic regression analysis was used to identify independent factors that were associated with hearing loss, combining pure-tone audiometry and VTMR testing. All statistical analyses were performed using SAS 9.2 (Cary, NC, USA); a two-sided $\mathrm{p}<0.05$ was considered significant.

\section{Results}

Three hundred eighty-four of the 1,300 volunteers interviewed were excluded from VTMR testing since they did not meet inclusion criteria. The following statistical analysis is based on the results obtained from the 916 subjects considered eligible to perform the whole audiological evaluation. Table I shows various characteristics of the subjects tested (age, sex and profession). None had single side deafness. Subjects were divided into two categories: normal and hearing-impaired on the basis of pure-tone audiometry. The results to the HHIEsf questionnaire are reported in Table II.

Figure 2 shows the ROC curves obtained from VTMR testing at a $\mathrm{S} / \mathrm{N}$ ratio of $0 \mathrm{~dB}$ (dotted grey line) and $-10 \mathrm{~dB}$ (continuous grey line). Since the AUC for a $\mathrm{S} / \mathrm{N}$ ratio of $-10 \mathrm{~dB}$ is greater, this $\mathrm{S} / \mathrm{N}$ ratio is more efficient in differentiating between normal and hearing impaired subjects. As shown in the graph, four correctly executed motor responses represent the cut-off value. This threshold expressed the highest value by the Youden's index (J) (Tab. III).

Table III shows the results of hearing impairment evaluation based on sensitivity, specificity and resulting Youden's index, of each value of VTMR speech audiometry with a

Table I. Subject characteristics.

\begin{tabular}{lccc} 
Characteristics & $\begin{array}{c}\text { Overall } \\
(\mathbf{n}=916)\end{array}$ & $\begin{array}{c}\text { Normal } \\
\leq 25 \mathrm{~dB} \mathrm{HL} \\
(\mathbf{n}=511)\end{array}$ & $\begin{array}{c}\text { Hearing loss } \\
\mathbf{2} 25 \mathrm{~dB} \mathrm{HL} \\
(\mathbf{n}=405)\end{array}$ \\
\hline Age $^{\mathrm{a}}$ & $55(42 ; 66)$ & $47(34 ; 57)$ & $64(55 ; 71)$ \\
\hline Sex $^{\mathrm{b}}$ & & & \\
$\mathrm{M}$ & $382(42.1 \%)$ & $166(32.4 \%)$ & $220(54.3 \%)$ \\
$\mathrm{F}$ & $530(57.9 \%)$ & $345(67.6 \%)$ & $185(45.7 \%)$ \\
Profession ${ }^{b}$ & & & \\
Housewife & $87(9.5 \%)$ & $44(8.6 \%)$ & $43(10.6 \%)$ \\
Retired & $278(30.4 \%)$ & $80(15.7 \%)$ & $198(48.9 \%)$ \\
Employee & $198(21.6 \%)$ & $151(29.6 \%)$ & $46(11.4 \%)$ \\
Student & $65(7.1 \%)$ & $60(11.7 \%)$ & $5(1.2 \%)$ \\
Workman & $73(8.0 \%)$ & $48(9.4 \%)$ & $25(6.2 \%)$ \\
Unemployed & $13(1.4 \%)$ & $9(1.9 \%)$ & $4(1.0 \%)$ \\
Teacher & $41(4.5 \%)$ & $35(6.9 \%)$ & $6(1.5 \%)$ \\
Manager/self employed & $108(11.8 \%)$ & $54(10.6 \%)$ & $54(13.3 \%)$ \\
\hline
\end{tabular}

a: data reported as median (1 ${ }^{\text {st }}$ quartile; $3^{\text {rd }}$ quartile); ${ }^{b}$ : data reported as frequencies (\%).
Table II. Results obtained with the HHIEsf questionnaire.

\begin{tabular}{lccc} 
& $\begin{array}{c}\text { Overall } \\
(\mathbf{n}=\mathbf{9 1 6})\end{array}$ & $\begin{array}{c}\text { Normal } \\
\leq 25 \mathrm{~dB} \mathrm{HL} \\
(\mathbf{n}=\mathbf{5 1 1})\end{array}$ & $\begin{array}{c}\text { Hearing loss } \\
\mathbf{2} 25 \mathrm{~dB} \mathrm{HL} \\
(\mathbf{n}=\mathbf{4 0 5})\end{array}$ \\
HHIEsf $^{\text {a }}$ & $6(2 ; 12)$ & $4(0 ; 8)$ & $8(4 ; 16)$ \\
Low $^{\mathrm{b}}$ & $602(100 \%)$ & $400(66.4 \%)$ & $202(33.6 \%)$ \\
Mild-to-moderate $^{\mathrm{b}}$ & $260(100 \%)$ & $91(35.0 \%)$ & $169(65.0 \%)$ \\
Severe $^{\text {b }}$ & $38(100)$ & $8(21.0 \%)$ & $30(79.0 \%)$ \\
\hline
\end{tabular}

${ }^{a}$ : data reported as median (1 ${ }^{\text {st }}$ quartile; $3^{\text {rd }}$ quartile); ${ }^{b}$ : data reported as frequencies (\%).

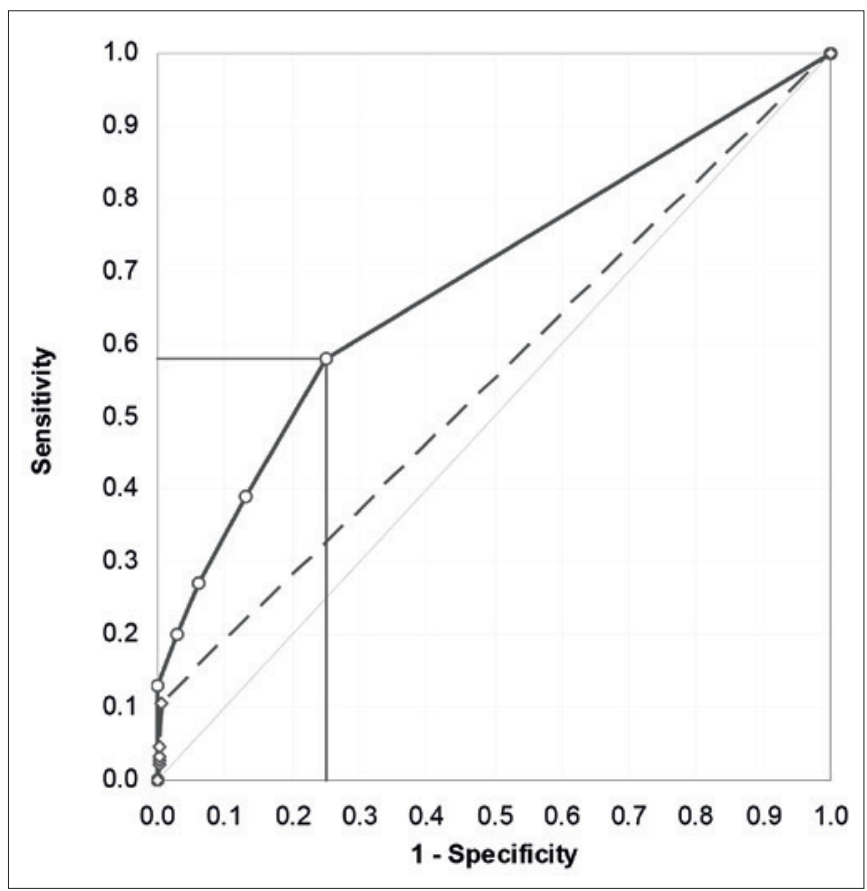

Figure 2. The ROC curves obtained from VTMR testing at a S/N ratio of $0 \mathrm{~dB}$ (dotted grey line) and $-10 \mathrm{~dB}$ (continuous grey line). Since the AUC for an $\mathrm{S} / \mathrm{N}$ ratio of $-10 \mathrm{~dB}$ is greater, this ratio is more efficient in differentiating between normal and hearing impaired subjects. As shown in the graph, the cut-off value is four correctly executed tasks since Youden's index is highest for this value.

$\mathrm{S} / \mathrm{N}$ ratio of $-10 \mathrm{~dB}$. When evaluating the self-perceived participation restrictions (HHIEsf $>24 / 40$ ), the sensitivity and specificity of VTMR testing increase to $78 \%$ and $63 \%$, respectively, at a $\mathrm{S} / \mathrm{N}$ ratio of $-10 \mathrm{~dB}$ with a cut-off of at least four correctly executed tasks. If hearing impairment and self-perceived severe participation restrictions are taken into account together, sensitivity and specificity further increased up to $90 \%$ and $62 \%$, respectively.

Table IV shows the distribution of normal hearing and hearing-impaired subjects in relation with the number of correct answers to the VTMR test (S/N $-10 \mathrm{~dB})$. While all normal hearing subjects answered correctly to the VMTR test by repeating all five motor tasks, only 170 of 405 hearing im- 
Table III. Sensitivity, specificity and Youden's index (J) for all possible threshold values of the VTMR test (S/N -10 dB) for hearing impairment and for hearing impairment and participation restriction (HHIEsf > 24/40).

\begin{tabular}{|c|c|c|c|c|c|c|c|c|c|}
\hline \multirow[b]{2}{*}{ VTMR } & \multicolumn{3}{|c|}{$\begin{array}{l}\text { Hearing } \\
\text { impairment }\end{array}$} & \multicolumn{3}{|c|}{$\begin{array}{l}\text { Participations } \\
\text { restriction }\end{array}$} & \multicolumn{3}{|c|}{$\begin{array}{c}\text { Hearing impairment } \\
\text { and participations restriction }\end{array}$} \\
\hline & Sensitivity & Specificity & $\mathrm{J}^{*}$ & Sensitivity & Specificity & $\mathrm{J}^{*}$ & Sensitivity & Specificity & $\mathrm{J}^{*}$ \\
\hline 0 & 0.13 & 1.00 & 0.13 & 0.32 & 0.95 & 0.28 & 0.44 & 1.00 & 0.44 \\
\hline 1 & 0.20 & 0.97 & 0.17 & 0.37 & 0.91 & 0.29 & 0.5 & 1.00 & 0.5 \\
\hline 2 & 0.27 & 0.94 & 0.21 & 0.5 & 0.86 & 0.36 & 0.64 & 0.87 & 0.5 \\
\hline 3 & 0.39 & 0.87 & 0.27 & 0.65 & 0.77 & 0.43 & 0.74 & 0.69 & 0.43 \\
\hline 4 & 0.58 & 0.75 & 0.33 & 0.78 & 0.63 & 0.40 & 0.90 & 0.62 & 0.53 \\
\hline 5 & 1.00 & 0.00 & 0.00 & 1.00 & 0.00 & 0.00 & 1.00 & 0.00 & 0.00 \\
\hline
\end{tabular}

paired subjects performed it correctly. Furthermore, when considering together the results at pure-tone audiometry and HHIEsf, only 3 subjects gave 5/5 correct answers to the VTMR: two women (44 and 37 years old with a score of 26/40 and 32/40) and one man (71 years old with a score of 28/40) with asymmetrical sensorineural hearing loss. In the normal hearing group, there were only two normally hearing subjects who reported a score of HHIEsf $>24 / 40$ (one 43-year-old man with a score of 30/40 and one 29-year-old woman with a score of 36/40): they returned a score of 5 correctly executed tasks at both $\mathrm{S} / \mathrm{N}$ ratios at the VTMR testing. In the group of hearing impaired subjects with low or mild-to-moderate participation restrictions, sensitivity was 0.51 and 0.60 and specificity was 0.90 and 0.77 , respectively. As reported in Table III, one or more mistakes $(<5 / 5)$ at VTMR testing $(\mathrm{S} / \mathrm{N}-10 \mathrm{~dB})$ allowed detection of subjects with hearing impairment and participation restriction (HHIEsf $>24 / 40$ ) with a good sensitivity and specificity ( 0.90 and 0.68 , respectively). The number of correctly executed motor responses at VTMR testing $(\mathrm{S} / \mathrm{N}-10 \mathrm{~dB})$ were significantly different in relation with sex, age and HHIEsf scores $(\mathrm{p}<0.0001)$. Table V compares pure-tone audiometry and VTMR testing using multiple logistic re-

Table IV. Distribution of normal hearing and hearing impaired subjects by the VTMR test (S/N -10 dB).

\begin{tabular}{lcc} 
VTMR & $\begin{array}{c}\text { Normal } \\
\leq 25 \mathrm{~dB} \mathrm{HL} \\
(\mathbf{n}=\mathbf{5 1 1})\end{array}$ & $\begin{array}{c}\text { Hearing loss } \\
>\mathbf{2 5} \mathrm{dB} \mathrm{HL} \\
(\mathbf{n}=\mathbf{4 0 5})\end{array}$ \\
0 & $1(0.2 \%)$ & $54(13.3 \%)$ \\
1 & $12(2.3 \%)$ & $26(6.4 \%)$ \\
2 & $20(3.9 \%)$ & $32(7.9 \%)$ \\
3 & $32(6.3 \%)$ & $49(12.1 \%)$ \\
4 & $61(11.9 \%)$ & $74(18.3 \%)$ \\
5 & $385(75.3 \%)$ & $170(42.0 \%)$ \\
\hline
\end{tabular}

Data reported as frequencies (\%).
Table V. Multiple logistic regression analysis of factors associated with hearing problems. Comparison between pure-tone audiometry results (pass/fail) and the VTMR test at S/N -10 dB (cut-off of 4 correctly executed motor responses).

\begin{tabular}{lccc} 
Characteristics & & $\begin{array}{c}\text { Pure-tone audiometry } \\
\text { OR }(\mathbf{9 5} \% \mathrm{Cl})\end{array}$ & $\begin{array}{c}\text { VTMR } \\
\text { OR }(\mathbf{9 5} \% \mathrm{Cl})\end{array}$ \\
\cline { 2 - 3 } Age & & 1 (ref) & $1(\mathrm{ref})$ \\
& $0-44$ & $4.9(3.2-7.6)$ & $2.5(1.7-3.7)$ \\
Sex & $65+64$ & $26.3(15.9-43.6)$ & $7.1(4.9-10.8)$ \\
& $\mathrm{F}$ & $1(\mathrm{ref})$ & $1(\mathrm{ref})$ \\
Disability & $\mathrm{M}$ & $2.8(2.0-3.9)$ & $1.5(1.1-2.0)$ \\
(HHIEsf) & Low & 1 (ref) & $1(\mathrm{ref})$ \\
& Mild-to- & & \\
& moderate & $3.7(2.6-5.3)$ & $1.5(1.1-2.1)$ \\
& Severe & $6.6(2.5-17.1)$ & $6.0(1.5-14.0)$ \\
\hline
\end{tabular}

OR: odds ratio.

gression analysis with a cut-off of 4 correctly executed motor responses. The difference between normal and hearing impaired subjects was statistically significant for all the considered variables. The results of the VTMR test were homogeneous with pure-tone audiometry, but were slightly more influenced by subjective self-perception (HHIEsf). The absence of partecipation restrictions in normally hearing subjects was clearly recognised by VTMR, compared with the severe partecipations restrictions in hearing impaired subjects (> 24/40) (Fig. 3). The AUC for a $\mathrm{S} / \mathrm{N}$ ratio of $-10 \mathrm{~dB}$ was 0.835 .

\section{Discussion}

As stated in ASHA guidelines, the identification of hearing losses exceeding a predetermined screening level (e.g. $25 \mathrm{~dB}$ HL) by pure tone audiometry across the frequency range of 1,000 to $4,000 \mathrm{~Hz}$ has shown an excellent sensitivity $(95-99 \%)$ and specificity $(78 \%-99 \%)^{15}$. Speech audiometry is a fundamental tool in audiological evaluation, aimed at examining the speech-processing abilities throughout the 


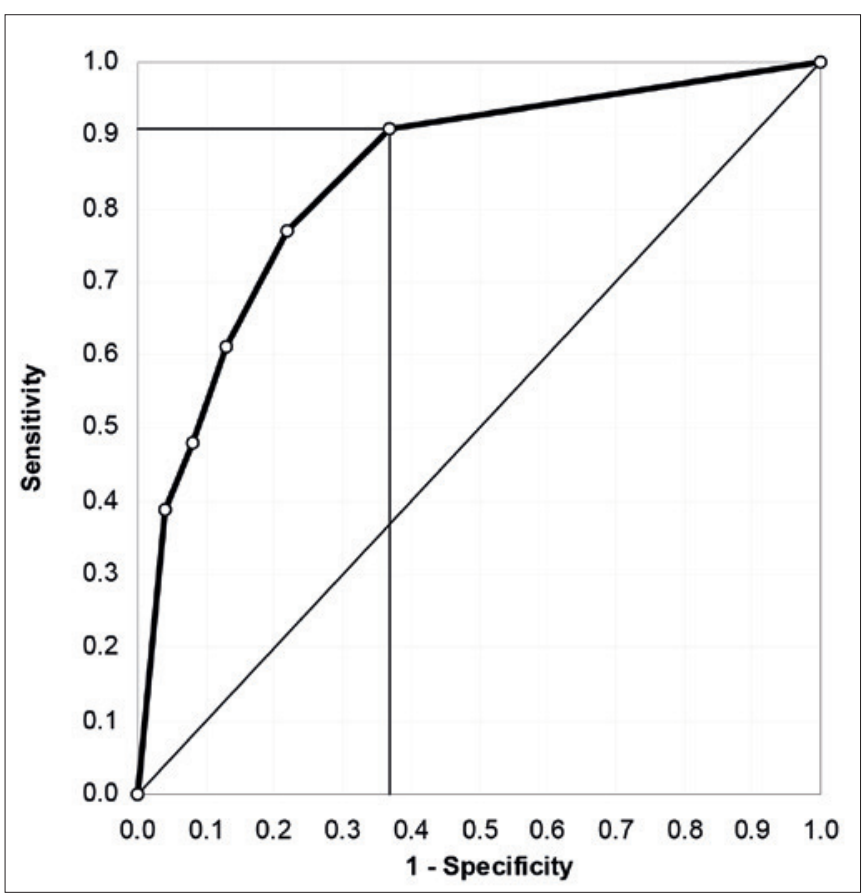

Figure 3. ROC curve obtained from VTMR testing at an $\mathrm{S} / \mathrm{N}$ ratio of $-10 \mathrm{~dB}$ (continuous line) of hearing impaired subjects with severe participation restrictions (HHIEsf $>24 / 40$ ). The AUC for an $\mathrm{S} / \mathrm{N}$ ratio of $-10 \mathrm{~dB}$ is 0.835 . As shown in the graph, the cut-off value is four correctly executed tasks since Youden's index is highest for this value.

auditory system; it can also be used to crosscheck the validity of pure-tone thresholds ${ }^{3}$. Speech tests have been proposed for adult hearing screening, but have shown widely different results depending on the protocol used; the reported sensitivity and specificity vary between $75 \%$ and $84 \%$ for the vowel-consonant-vowel ${ }^{6}$, and $91-93 \%$ for the digit triplet speech test in noise ${ }^{15,16}$. In our study, the sensitivity and specificity of speech comprehension in noise with VTMR test was even lower (58\% and 75\%) than those of other speech tests when used to screen only peripheral function. In this respect, our findings support the well known advantage of pure tone audiometry for assessment of peripheral hearing impairment ${ }^{14}$. Nevertheless, many studies have shown that the ability to comprehend speech in challenging (e.g. noisy or reverberant) listening situations is influenced either by bottom-up peripheral auditory processes and by top-down cognitive abilities ${ }^{5,17-22}$. However, as reported by Jerger et al., only the synthetic sentence identification (SSI) test and dichotic sentence identification (DSI) are related to cognitive abilities ${ }^{23}$.

Difficulty in speech understanding in noisy conditions is one of the most notorious complaints of people with hearing; it is often related to self-perceived hearing disability. In the audiological diagnostic work-up, speech-in-noise tests based on sentences are widely accepted as appropriate tools for assessment of a subject's ability to understand speech in noisy and daily-life situations ${ }^{24}$. However, when proposed as a unique measure of hearing impairment and disability in adult hearing screening programs, the results of speech tests, such as the Synthetic Sentence Identification test, Speech Perception in Noise at an $\mathrm{S} / \mathrm{N}$ ratio of $+8 \mathrm{~dB}$, Dichotic Sentence Identification test and degraded word recognition tasks, were sometimes unsatisfactory or insufficiently reliable, and many authors have concluded that they should have been improved ${ }^{25-28}$. Matthews et al (1990) reported a lack of correlation between Speech Perception in Noise test and total scores on the HHIE ${ }^{29}$.

Conversely, when we took into account a measure of severe self-perceived difficulty in comprehension of speech in noisy conditions, the VTMR test in noise at the pre-set cut-off value of 4 of 5 correctly executed tasks correlated well, with the hearing loss identified by pure tone audiometry and the self-report measure of participation restriction: sensitivity and specificity were 0.90 and 0.62 , respectively. This finding might be justified by the fact that the VTMR test does not only quantify speech understanding in noise, but combines visual identification, working memory, speech comprehension and motor execution ${ }^{8}$. The VTMR test, in fact, is more redundant than other speech tests, and therefore it might more closely resemble the difficulty and disability experienced by a hearing-impaired individual, especially in the absence of appropriate auxiliary aids and proper support for effective communication.

When attempting to demonstrate a difference in speech comprehension between normal and hearing impaired subjects, a $\mathrm{S} / \mathrm{N}$ ratio of $-10 \mathrm{~dB}$ was more effective than a $\mathrm{S} / \mathrm{N}$ of $0 \mathrm{~dB}$. This finding suggests that a $\mathrm{S} / \mathrm{N}-10 \mathrm{~dB}$ better exploits the redundancy of information implied by the selected tasks. Further advantages of the VTMR testing at an $\mathrm{S} / \mathrm{N}$ ratio of $-10 \mathrm{~dB}$ with a cut-off of four of five correctly executed tasks are rapidity, low-cost, high specificity and feasibility, which are all useful characteristics in a screening setting.

It has been demonstrated to be a user-friendly test with a high level of redundancy, since it is based on a set of familiar objects whose function is intrinsic, e.g.: the hammer is obviously meant to hit the sticks. The results of the VTMR test are clearly understandable by subjects and may motivate them to seek audiological help. However, a limit of this study is the lack of comparison with other sentences in noise tests; the results cannot be easily transferred to a clinical diagnostic setting: in order to do that, repeatability should be established, by determining consistency over repeated measures and test-rest variability, which is not feasible in a screening setting. In our previous work, 
the comparison between VTMR and traditional speech test with bysillabic words was performed in quiet, showing a good correlation between the two tests ${ }^{8}$.

\section{Conclusions}

Speech in noise tests using the VTMR test instructions were highly sensitive in distinguishing subjects with disabling hearing loss; the risk of false negative results was significantly reduced.

Our findings suggest that this method might be used as a stand-alone tool to simultaneously screen for impairment and participation restrictions, which are complementary and equally important aspects of any adult hearing screening programme.

\section{Acknowledgements}

We wish to thank Dr Dario Alpini and Prof Antonio Cesarani for the conceptual planning of the research and in particular Prof Antonio Cesarani for VTMR test invention and for data setting; Ing. Gabriella Tognola, Dr Daniela Soi, Dr Elisabetta Iacona, and Dr Daniela Ginocchio for the field data collection. We thank the Health Department of Comune di Milano for the management and use of its facilities.

\section{References}

1 Davis A, Smith P, Ferguson M, et al. Acceptability, benefit and costs of early screening for hearing disability: a study of potential screening tests and models. Health Technol Assess 2007;11:145-7.

2 Smith PA, Davis AC, Pronk M, et al. Adult hearing screening: what comes next? Int J Audiol 2011;50:610-2. https://doi.org/10.3109/149 92027.2011.585668

3 American Speech-Language-Hearing Association. Guidelines for audiologic screening. ASHA Suppl 1997;39:15-29.

4 Newman CW, Jacobson GP, Hug GA, et al. Perceived hearing handicaps by patients with unilateral or mixed hearing loss. Ann Otol Rhinol Laryngol 1997;106:210-4. https://doi. org/10.1177/000348949710600305

5 Pichora-Fuller MK, Singh G. Effects of age on auditory and cognitive processing: implications for hearing aid fitting and audiological rehabilitation. Trends Amplif 2006;10:29-59. https://doi. org/10.1177/108471380601000103

6 Paglialonga A, Grandori F, Tognola G. Using the speech understanding in noise (SUN) test for adult hearing screening. Am J Audiol 2013;22:171-4. https://doi.org/10.1044/1059-0889(2012/12-0055)

7 Danermark B, Granberg S, Kramer SE, et al. The creation of a comprehensive and a brief core set for hearing loss using the International Classification of Functioning, Disability and Health. Am J Audiol 2013:22:323-8. https://doi.org/10.1044/10590889(2013/12-0052)

8 Di Berardino F, Forti S, Cesarani A. VTMR, a new speech audiometry test with verbal tasks and motor responses. Ann Otol Rhinol Laryngol 2012;121:253-60. https://doi.org/10.1177/000348941212100411

9 Di Berardino F, Forti S, Iacona E, et al. Public awareness of ear and hearing management as measured using a specific questionnaire. Eur
Arch Otorhinolaryngol 2013:270:449-53. https://doi.org/10.1007/ s00405-012-1961-3

10 American National Standards Institute (ANSI). Maximum permissible ambient noise levels for audiometric test rooms. New York: Acoustical Society of America; 1991.

11 American National Standards Institute (ANSI). Specification for audiometers. New York: Acoustical Society of America; 2010.

12 Ventry IM, Weinstein BE. Identification of elderly people with hearing problems. ASHA 1983;25:37-42.

13 Cox R. Assessment of subjective outcome of hearing aid fitting: getting the client's point of view. Int J Audiol 2003;42:S90-6.

14 Lichtenstein MJ, Bess FH, Logan SA. Diagnostic performance of the hearing handicap inventory for the elderly (screening version) against differing definitions of hearing loss. Ear Hear 1988;9:208-11. https:// doi.org/10.1097/00003446-198808000-00006

15 Frank T, Petersen DR. Accuracy of a $40 \mathrm{~dB}$ HL Audioscope ${ }^{\mathrm{TM}}$ and audiometer screening for adults. Ear Hear 1987;8:180-3. https://doi. org/10.1097/00003446-198706000-00009

16 Smits C, Kapteyn TS, Houtgast T. Development and validation of an automatic speech-in-noise screening test by telephone. Int J Audiol 2004; $43: 15-28$.

17 Smits C, Houtgast T. Results from the Dutch speech-in-noise screening test by telephone. Ear Hear 2005;26:89-95. https://doi. org/10.1097/00003446-200502000-00008

18 Houtgast T, Festen JM. On the auditory and cognitive functions that may explain an individual's elevation of the speech reception threshold in noise. Int J Audiol 2008;47:287-95. https://doi. org/10.1080/14992020802127109

19 Humes LE, Christopherson L. Speech identification difficulties of hearing-impaired elderly persons: the contributions of auditory processing deficits. J Speech Hear Res 1991;34:686-93. https://doi. org/10.1044/jshr.3403.686

20 Pichora-Fuller MK, Schneider BA, Daneman M. How young and old adults listen to and remember speech in noise. J Acoust Soc Am 1995;97:593-608. https://doi.org/10.1121/1.412282

21 Rönnberg J. Cognition in the hearing impaired and deaf as a bridge between signal and dialogue: a framework and a model. Int J Audiol 2003;42:S68-76.

22 Wingfield A. Cognitive factors in auditory performance: context, speed of processing, and constraints of memory. J Am Acad Audiol 1996; 7:175-82.

23 Jerger J, Jerger S, Pirozzolo F. Correlational analysis of speech audiometric scores, hearing loss, age, and cognitive abilities in the elderly. Ear and Hearing 1991;12:2:103-9. https://doi.org/10.1097/00003446199104000-00004

24 Kramer SE, Kapteyn TS, Festen JM. The self-reported handicapping effect of hearing disabilities. Audiology 1998;37:302-12.

25 Fire KM, Lesner SA, Newman C. Hearing handicap as a function of central auditory abilities in the elderly. Am J Otol 1991;12:105-8.

26 Jerger J, Oliver T, Pirozzolo F. Impact of central auditory processing disorder and cognitive deficit on the self-assessment of hearing handicap in the elderly. J Am Acad Audiol 1990;1:75-80.

27 Gatehouse S. The contribution of central auditory factors to auditory disability. Acta Otolaryngol Suppl 1990a;476:182-8. https://doi. org/10.3109/00016489109127276

28 Gatehouse S. The role of non auditory factors in measured and selfreported disability. Acta Otolaryngol Suppl 1990b;476:249-56.

29 Matthews LJ, Lee FS, Mills JH, et al. Audiometric and subjective assessment of hearing handicap. Arch Otolaryngol Head Neck Surg 1990;116:1325-30. https://doi.org/10.1001/archotol.1990.01870110097013 